\title{
Investment Strategies, Performance, And Trading Information Impact
}

Tov Assogbavi, (Email: tassogbavi@laurentian.ca), Laurentian University, Canada

Johnston E. Osagie, Florida A\&M University

Larry A. Frieder, Florida A\&M University

Jong-Kyun Shin, Laurentian University, Canada

\begin{abstract}
This paper examines a set of investment strategies based on past market information to evaluate performance and trading impact on the Canadian Market ${ }^{1}$. In doing so, we assess whether trading information adds value to the effectiveness of these strategies. Utilizing variant models of four different methodologies, we find strong evidence that supported the Momentum Investment Strategy, which buys past winner stocks and sells past loser stocks. Our evidence did not support Contrarian Investment Strategy, which posits that investors overreact to good and bad news. Our winners' portfolios outperform our losers' portfolios. The Negative Volume Effect Strategy did not work, which is contrary to the Foerster, Prihar and Schmitz (1995) study. We found that winners' stocks did not reverse in cases of heavy volume; nor did loser stocks reverse in a high volume context. However, we did find that trading information has an impact on stock returns and thus adds value to investment strategies for the 1990 to 2000 investment period. Investors who combine past price and trading volume information in constructing their investment strategies would achieve higher returns than investors who base their portfolio construction decisions solely on stock prices.
\end{abstract}

\section{INTRODUCTION}

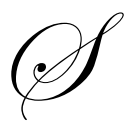

ince the dawn of modern finance, there has been a long debate and research on whether historical data on stocks is useful information in forecasting stock price changes. According to the weak form of the Efficient Market Hypothesis, it is impossible to forecast market direction based on past data. Nevertheless, many researchers, DeBondt and Thaler (1985), Jegadeesh and Titman (1993), Assogbavi, Khoury, and Yourougou (1995) Baytas and Nusret (1999), Dirk, DeBondt and Weber (1999), Mun, Vasconcellos, and Kish (2000), have challenged this hypothesis by showing that investors can achieve abnormal returns using investment strategies based on past market data such as price and trading volume. Recent findings by Chordia and Swaminathan (2000), and Gervais, Kaniel and Mingelgrin (2001), on investment strategies based on historical data tend to confirm that past stock price and trading volume provide valuable information in predicting market direction and stock returns. Accordingly, practitioners should consider using past market information in constructing investment portfolios. However, depending on the strategy, the methodology utilized may seem at times to be contradictory. For instance, while contrarian investment strategies recommend buying past losers and selling past winners, momentum strategies recommend buying past winners and selling past losers. From a practitioner standpoint, knowing which of these investment strategies to apply becomes very challenging. The main objective of this paper, is to investigate different strategies based upon previous studies such as those by DeBondt and Thaler (1985, contrarian), Jegadeesh and Titman (1993, momentum), Conrad, Hameed, and Niden (1994, negative volume effect), and Gervais, Kaniel and Mingelgrin (2001, positive volume effect), as well as to provide a better understanding of utilizing these strategies on the Canadian stock market using the Toronto Stock Exchange (TSE) 100. Additionally, the extent to which trading information adds value to the robustness of these investment strategies is assessed.

\footnotetext{
${ }^{1}$ The authors acknowledge research support from CISRO Institute of Management at Laurentian University.
} 
The remainder of the paper is as follows: Section II presents a brief review of the literature; in Section III the data and methodologies are described; Section IV summarizes results and Section V indicates our conclusions.

\section{LITERATURE REVIEW}

There are many published studies on contrarian/momentum investment strategies. The earliest and most influential work on contrarian investment strategy was done by DeBondt and Thaler (1985), who found that when U.S. stocks were ranked on their returns over the past three to five years, those with the lowest past returns earn higher returns over the subsequent three to five years, and vice versa. Baytas and Nusret (1999) reported that long-term contrarian strategies in the other seven industrialized countries seem to have significant returns. Dirk, DeBondt and Weber (1999) found that contrarian strategies in Germany appear to be profitable. Mun, Vasconcellos, and Kish (2000) tested contrarian strategies in the U.S. and Canadian markets over the period of 1986 to 1996 . Their results also show that the contrarian returns in this period were less significant in Canada than in the U.S.

As far as momentum investment strategy is concerned, one of the earliest studies done by Jegadeesh and Titman (1993) on the NYSE and the AMEX reported that a momentum strategy that buys the last 12 month top performer stocks and keeps them for just 3 months can earn as much as $1.49 \%$ per month. Cleary and Inglis (1998) also support the momentum strategy with a study based on Canadian common stocks during the period of 1978-1990. Rouwenhorst (1998) shows that momentum strategies worked in twelve European countries. Rouwenhorst (1999) also reported also emerging market stocks exhibited momentum. Dirk, De Bondt, and Weber (1999) reported that momentum and contrarian strategies appeared to beat a passive approach that invested in the market index of all major companies listed on the Frankfurt Stock Exchange of Germany for the 1961-1991 period. Chan, Hameed, and Tong (2000) showed statistically significant evidence of momentum profits derived from international stock market indices. Assogbavi and Dodge (2002) found that a momentum strategy that invested in medium-horizon "Winners" and sold past "Losers" gained approximately 2 percent per month in the Nigeria Stock Exchange.

With respect to trading volume, Campbell, Grossman, and Wang (1993) suggested that the first-order daily return autocorrelation tended to decline with volume. Blume, Easley, and O'Hara (1994) indicated that volume provided insights about information quality which could not be deduced from price statistics. Conrad, Hameed, and Niden (1994) presented strong evidence of a relationship between trading activity and subsequent autocovariances in weekly returns. Specifically, high-transaction securities experienced price reversal, while the returns of lowtransaction securities were positively autocovarying. Assogbavi, Khoury, and Yourougou (1995) confirmed an asymmetry in the price-volume relationship in equity markets using Canadian data. Datar, Vinay, Naik and Radcliffe (1998) pointed out that low turnover stocks generally earn higher returns than high turnover stocks. Chordia and Swaminathan (2000) reported that daily and weekly returns on high volume portfolios led returns on low volume portfolios because returns on low volume portfolios responded more slowly to information about market returns. Lee and Swaminathan (2000) asserted that firms with high (low) past turnover ratios earn lower (higher) future returns, and have consistently more negative (positive) earnings surprises over next eight quarters. Price momentum effects reverse over the next five years, and high (low) volume winners (losers) experience faster reversals. Gervais, Kaniel and Mingelgrin (2001) suggested that stocks experiencing unusually high (low) trading volume over a day or a week tended to appreciate (depreciate) over the course of the following month. The common ground of all of these studies is that past information is invaluable for predicting future market trends and individual stock returns. The purpose of this study is to analyze the performance of a set of investment strategies based upon past market information, from the Canadian stock market (the TSE). In doing so, the importance of trading information in these investment strategies for the investment period of 1990 to 2000 is established.

\section{DATA AND METODOLOGY}

\section{Data Description}

The data used in this study consists of daily trading volumes and prices from January 1990 to February 2000 on 100 stocks that made up the TSE 100 index. The TSE 100 Index includes 100 of the largest and most liquid stocks traded on the TSE. It represents two-thirds of the capitalization of the Canadian equity market. The TSE is the 
Canada's premier market for senior equities, accounting for approximately $95 \%$ of all equity trading in Canada. In 2000 , more than 40 billion shares valued at $\$ 944$ billion were traded.

\section{Methodology}

For comparison purposes, the methodologies used in this paper to evaluate the performance of contrarian/momentum investment strategies are adapted from previous articles on similar subjects with minor modifications. Specifically, our methodologies are based on four different articles; DeBondt and Thaler (1985) for the Contrarian strategy; Jegadeesh and Titman (1993) for the Momentum strategy; Conrad, Hameed, and Niden (1994) for the Negative volume effect; and Gervais, Kaniel and Mingelgrin (2001) for the Positive volume effect. In these four analyses, the original ideas and approaches are followed as closely as possible.

\section{ANALYSES AND RESULTS}

\section{Contrarian Strategy}

The Contrarian Strategy is related to the overreaction hypothesis which assumes that most people tend to "overreact" to unexpected and dramatic news events. Some economists such as Basu (1977) and Dreman (1982) believe that the same behavior occurs in stock markets. In other words, they think that stock prices are overvalued in case of good news and undervalued in case of bad news, but eventually return to more appropriate, less inflated or less deflated values. Based on this hypothesis, DeBondt and Thaler (1985) designed an empirical test due to the fact that: (1) Extreme movements in stock prices will be followed by subsequent price movements in the opposite direction. (2) The more extreme the initial price movement, the greater will be the subsequent adjustment. We follow DeBondt and Thaler's (1985) empirical test design that bought past losers and sold past winners. Our empirical test results, after correcting for missing data problems and for the time frame of this study, are presented in Table I.

Winner portfolios were composed of top $10 \%$ stocks in terms of returns in formation periods. Loser portfolios were composed of bottom $10 \%$ stocks in terms of returns in formation periods. The returns of winner portfolios and loser portfolios were calculated over three year holding periods following a three year formation period. Average annual return is calculated by dividing Average Return for three years of the holding period by three.

For every stock j, starting in December 1992 (month 36; the "portfolio formation date", we compute the cumulative returns $\mathrm{R}_{\mathrm{jt}}$ for the prior 36 months or three-year period (the "portfolio formation" period, months 1 through 36). $\mathrm{R}_{\mathrm{jt}}$ is calculated as below;

$$
R_{j t}=\frac{P_{j t L}-P_{j t F}}{P_{j t F}}
$$

where $\mathrm{R}_{\mathrm{jt}}=$ cumulative return in a given stock $\mathrm{j}$ for the $\mathrm{t}^{\text {th }}$ formation period of three-year duration starting in January $1990 ; \mathrm{P}_{\mathrm{jtF}}=$ the price of a given stock $\mathrm{j}$ on the first day of the $\mathrm{t}^{\text {th }}$ formation period; $\mathrm{P}_{\mathrm{jtL}}=$ the price of a given stock $\mathrm{j}$ on the last day of the $\mathrm{t}^{\text {th }}$ formation period.

Then we rank the top decile as the winner portfolio and the bottom decile as the loser portfolio. The portfolios are then formed based on the ranking prior to $t=0$, the portfolio formation date. For both winner and loser portfolios in the subsequent three-year test period (month 37 through month 72), we compute the cumulative average returns of all securities in the portfolio. Similar computation is done for subsequent periods ending in December 1993, 1994, 1995, and 1996. In Panel A, X is the annual average return (in percent) of portfolios, and Sx is the sample standard deviation in percentage terms. Panel B shows the annual return for winner and loser portfolios for five overlapping periods. 
Table I. Summary Statistics of Performance of Contrarian Strategy ${ }^{2}$

\begin{tabular}{|c|c|c|c|c|c|}
\hline \multicolumn{6}{|c|}{ Panel A: Overall Sample Average Returns and Standard Deviations in percentages } \\
\hline & $\mathbf{X}$ & $\mathbf{S x}$ & Min & Max & t-statistic \\
\hline Winner & 66.72 & 45.40 & 34.08 & 141.94 & 3.29 \\
\hline Loser & 40.12 & 14.15 & 23.44 & 58.62 & 6.34 \\
\hline \multicolumn{6}{|c|}{ Panel B: Return for five overlapping periods in percentages } \\
\hline \multicolumn{2}{|c|}{ Formation period } & Test period & \multicolumn{2}{|c|}{ Winner } & Loser \\
\hline \multicolumn{2}{|c|}{ 1990-1992 } & 1993-1995 & \multicolumn{2}{|c|}{43.01} & 23.44 \\
\hline \multicolumn{2}{|c|}{ 1991-1993 } & 1994-1996 & \multicolumn{2}{|c|}{34.08} & 30.09 \\
\hline \multicolumn{2}{|c|}{ 1992-1994 } & 1995-1997 & \multicolumn{2}{|c|}{77.06} & 39.46 \\
\hline \multicolumn{2}{|c|}{ 1993-1995 } & 1996-1998 & \multicolumn{2}{|c|}{37.51} & 58.62 \\
\hline \multicolumn{2}{|c|}{ 1994-1996 } & 1997-1999 & \multicolumn{2}{|c|}{141.94} & 49.01 \\
\hline
\end{tabular}

In total, we generate five test results with overlapping periods. Our findings presented on Table I indicate that the returns of winner portfolios are higher than those of loser portfolios except for the test period of 1996 to 1998 . On average, for the periods of 1993 to 1999 , winner portfolios achieved $66.72 \%$ annual return $(\mathrm{t}-\mathrm{statistic}=3.29)$ and loser portfolios achieved $40.12 \%$ annual return ( $\mathrm{t}$-statistic $=6.34)$. Both values are statistically significant. Therefore, it seems that contrarian strategy did not work for 1990s' TSE 100 stocks counter to the belief that loser portfolios are supposed to outperform winner portfolios according to the overreaction hypothesis or contrarian strategy. A possible explanation of the failure of contrarian strategy may be related to the fact that Canadian stock market was a bull market in the 1990's. Average annual market return for TSE 100 between 1993 and 1999 was 24.79\%. However, loser portfolios still outperformed the market return by over $15 \%$. Therefore, one cannot say contrarian strategy totally failed for this period.

\section{Momentum Strategy (Or Relative Strength Strategy)}

The momentum investment strategy is based on the assumption that stocks under-react to arrival of new information as opposed to the contrarian strategy. It suggests that one buy past winners and sell past losers. The approach used in this study is a variant of what Jegadeesh and Titman (1993) used in their study. Our empirical test results are presented in Table II. The results correct for missing data and the time frame.

For every stock j, starting in December 1990 (month 12; the "portfolio formation date"), we compute the cumulative returns $\mathrm{R}_{\mathrm{jt}}$ for the prior 12 months or one-year period (the "portfolio formation" period, months 1 through 12). Divergent to the contrarian, the momentum strategy buys the winners (top decile portfolio) and sells the losers (bottom decile portfolio). Next, the return for each portfolio in the subsequent one-quarter test period (month 13 through month 15) is computed. The process is then repeated throughout December 1999 to generate 12-month formation and 3-month holding period momentum portfolio. Winner portfolios were composed of top $10 \%$ stocks in terms of returns during formation periods of one year. Loser portfolios were composed of bottom 10\% stocks in terms of returns during formation periods of one year. The returns of winner portfolios and loser portfolios were calculated over subsequent three months or a quarter of holding periods.

The annual return for each year was compounded from quarterly returns using the following equation:

Annual Return $=((1+\mathrm{Q} 1 / 100) *(1+\mathrm{Q} 2 / 100) *(1+\mathrm{Q} 3 / 100) *(1+\mathrm{Q} 4 / 100)-1) * 100$

Table II below presents our major findings. In Panel A, $\mathrm{X}$ is the annual average return (in percent) for each portfolio, and $\mathrm{Sx}$ is the sample standard deviation in percentage terms. Panel B shows returns for loser and winner portfolio for each year.

\footnotetext{
${ }^{2}$ The "C" computer program developed to generate these results is available from the authors on request.
} 
The results are quite consistent with what Jegadeesh and Titman (1993) reported for U.S. market and what Foerster et al (1995) did with the Canadian market for 1977 to 1992 . For the quarterly returns, winner portfolios outperformed loser portfolios 27 quarters out of 36 quarters for the nine-year period between 1991 and 1999. Winners showed a $75 \%$ winning rate over losers. For the annual returns, winner portfolios always outperformed loser portfolios for the same period.

Table II. Summary Statistics of returns of Momentum Strategy in percent

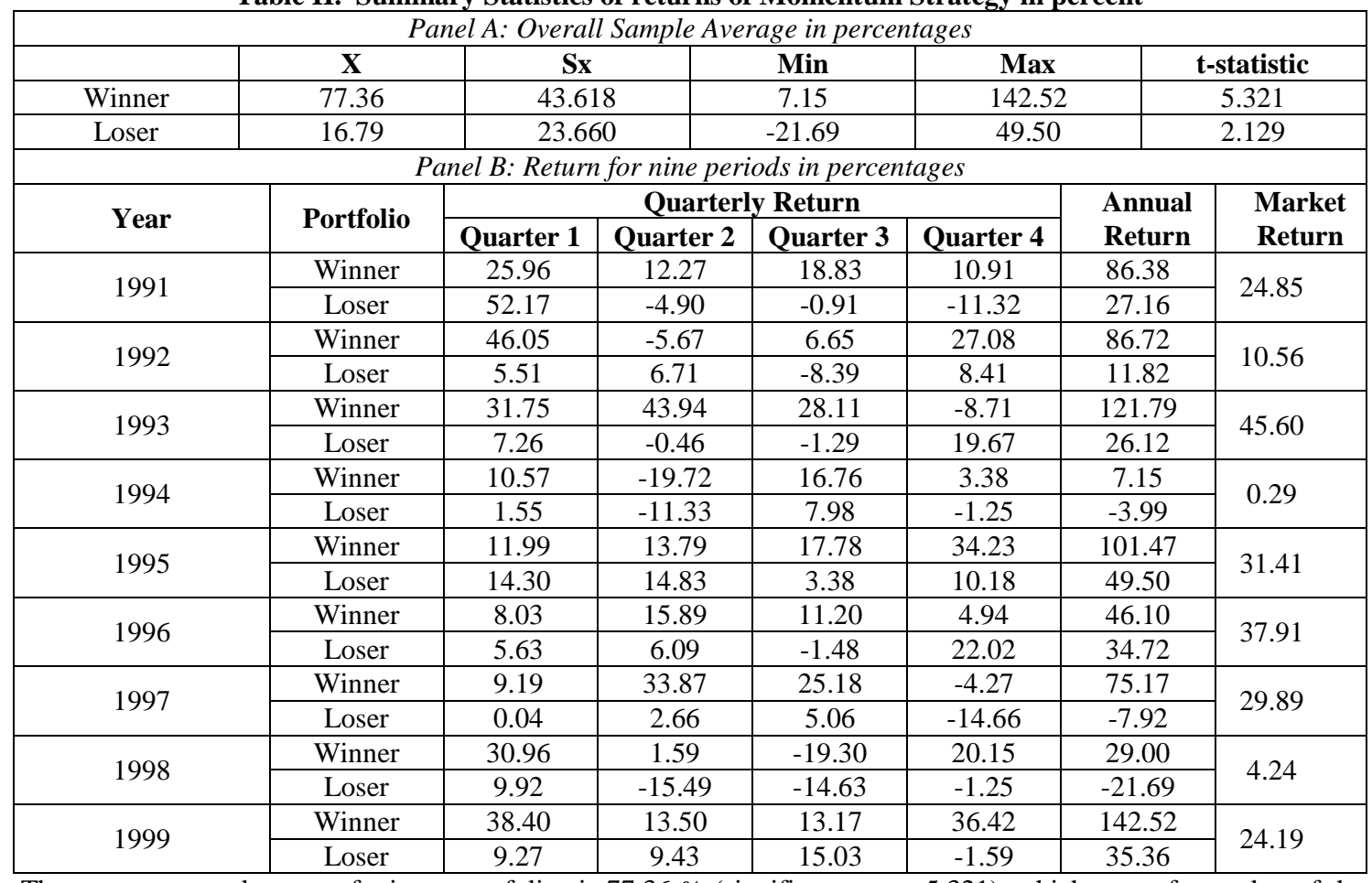

The average annual return of winner portfolios is $77.36 \%$ (significant at $\mathrm{t}=5.321$ ), which outperforms that of the loser portfolios, $16.79 \%$ (significant at $\mathrm{t}=2.129$ ) and the market $23.22 \%$. The performance of this strategy is quite substantial from 1990 to 2000, which was a boom period for the Canadian market.

\section{Positive Volume Effect Strategy (High Volume Return Premium)}

This strategy uses trading volume as an exclusive predictor of future prices. Using this approach, Gervais, Kaniel, and Mingelgrin (2001) reported that individual stocks whose trading activity is unusually large (small) over periods of a day or a week, as measured by trading volume during those periods, tend to experience large (small) returns over the subsequent month. They postulated that this result is due to shocks in trader interest in a given stock, that is, the stock's visibility. Following Gervais, Kaniel, and Mingelgrin (2001), we construct our methodology and conduct our analysis as follows. First, we construct our sample by splitting the period between January 1990 to December 1999 into 51 nonintersecting trading intervals of 50 trading days. The first interval is used only for formation and reference purpose. Each formation period of 50-days trading interval is split into a reference period and a formation date, which, respectively, consists of the first 49 days and the last day of the interval. The number of shares traded is used as the measure of trading volume. For a given formation period, a stock is classified as a high(low-) volume stock if its formation date volume is among the top 10 percent (bottom 10 percent) of 50 daily trading volumes. Otherwise, it is classified as a normal volume stock. At the formation date, we form high- (low) volume portfolios based on the stock's trading volume classification. After the portfolios are formed, they are held without 
any rebalancing over the next 50 -days trading interval which is the holding or the test period ${ }^{3}$. The average returns for both portfolios in a given test period, $\mathrm{X}_{\mathrm{p}}$ is computed as below;

$$
X_{p}=\frac{1}{N_{p}} \sum_{j=1}^{N_{p}}\left(\frac{P_{j L}-P_{j F}}{P_{j F}}\right)
$$

Where $N_{p}=$ the number of stocks in the high volume portfolio $(p=H)$ or the low volume portfolio $(p=L) ; P_{j F}=$ the price of a given stock $\mathrm{j}$ on the first day of the test period in the high volume portfolio or the low volume portfolio; $\mathrm{P}_{\mathrm{jL}}$ $=$ the price of a given stock $\mathrm{j}$ on the Last day of the test period in the high volume portfolio or the low volume portfolio. The periodic returns of high portfolios and low portfolios were calculated over subsequent holding period of 50 trading days.

The annual return for each year was compounded from periodic returns using the following equation;

Annual Return $=((1+\mathrm{P} 1 / 100) *(1+\mathrm{P} 2 / 100) *(1+\mathrm{P} 3 / 100) *(1+\mathrm{P} 4 / 100) *(1+\mathrm{P} 5 / 100)-1) * 100$

The findings are presented in Table III below. In Panel A, X is the annual average return (in percent) of each portfolio, and Sx is the sample standard deviation in percentage terms. Panel B shows returns for High and Low portfolio for each year.

Our results in Table III show that the periods of extremely high volume tend to be followed by positive excess returns, while periods of extremely low volume tend to be followed by even larger positive excess returns in $1990-2000$ periods for TSE 100 stocks. The average annual return for high volume stocks, $24.27 \%$ (significant at $\mathrm{t}=$ 3.087 ) is higher than the market return of $19.69 \%$ but the average annual return for low volume stocks, $35.83 \%$ (significant at $\mathrm{t}=3.236$ ) is even higher than that of high volume stocks. For the investment periods considered, high volume stocks outperform low volume stocks only in 24 periods out of total 50 periods tested. For individual years, the results of only two years, 1990 and 1992, were consistent with the findings of Gervais, Kaniel, and Mingelgrin (2001) on the NYSE that show that high volume tend to be followed by positive excess returns, whereas periods of low volume tend to be followed by negative excess returns. However, an interesting point is that average annual return of high volume stocks, $24.27 \%$ is still higher than that of the market, $19.69 \%$.

\section{Negative Volume Effect}

One important implication of the paper of Campbell, Grossman, and Wang (1993) is that "price change accompanied by high volume tend to be reversed; this will be less true of price changes on days with low volume." Conrad, Hameed, and Niden (1994) tried to test for this relation between lagged volume and price suggested by Campbell, Grossman, and Wang (1993) using a strategy varied from what Lehmann (1990) proposed. Following Conrad, Hameed, and Niden (1994), the methodology used in this analysis is as follows. For each week (week t), we calculate $\mathrm{u}_{\mathrm{it}-1}$, the measure of abnormal trading in security $\mathrm{i}$ at week $\mathrm{t}-1$ or previous week as follow:

$$
\mathrm{u}_{\mathrm{it}-1}=\left(\mathrm{Vit}_{-1}-\mathrm{V}_{\mathrm{it}-2}\right) / \mathrm{V}_{\mathrm{it}-2}
$$

where $\mathrm{V}_{\mathrm{it}-1}$ and $\mathrm{V}_{\mathrm{it}-2}$ are the sums of the trading volumes in security i for week $\mathrm{t}-1$ and $\mathrm{t}-2$, respectively. A positive $\mathrm{u}_{\mathrm{it}-1}$ is considered a positive trading shock or high-transaction security; a negative $\mathrm{u}_{\mathrm{it}-1}$ is taken as a negative trading shock or low-transaction security ${ }^{4}$. For each week (week $t$ ), we calculate $\mathrm{R}_{\mathrm{it}-1}$, the return of security $\mathrm{i}$ (in percent) at week t-1

\footnotetext{
${ }^{3}$ Gervais, Kaniel, and Mingelgrin (2001) report that at a horizon of 50 to 100 days the profits seem to level off or even decline. In addition, the profits of shorter trading days does not warrant transaction fee.

${ }^{4}$ We use the volume as a measure of trading in the security even though Conrad, Hameed, and Niden (1994) use the number of transaction, for they suggest that, using their method, volume and the number of transactions measure are roughly the same.
} 
Table III. Summary Statistics of Returns of Positive Volume Effect Strategy in percent

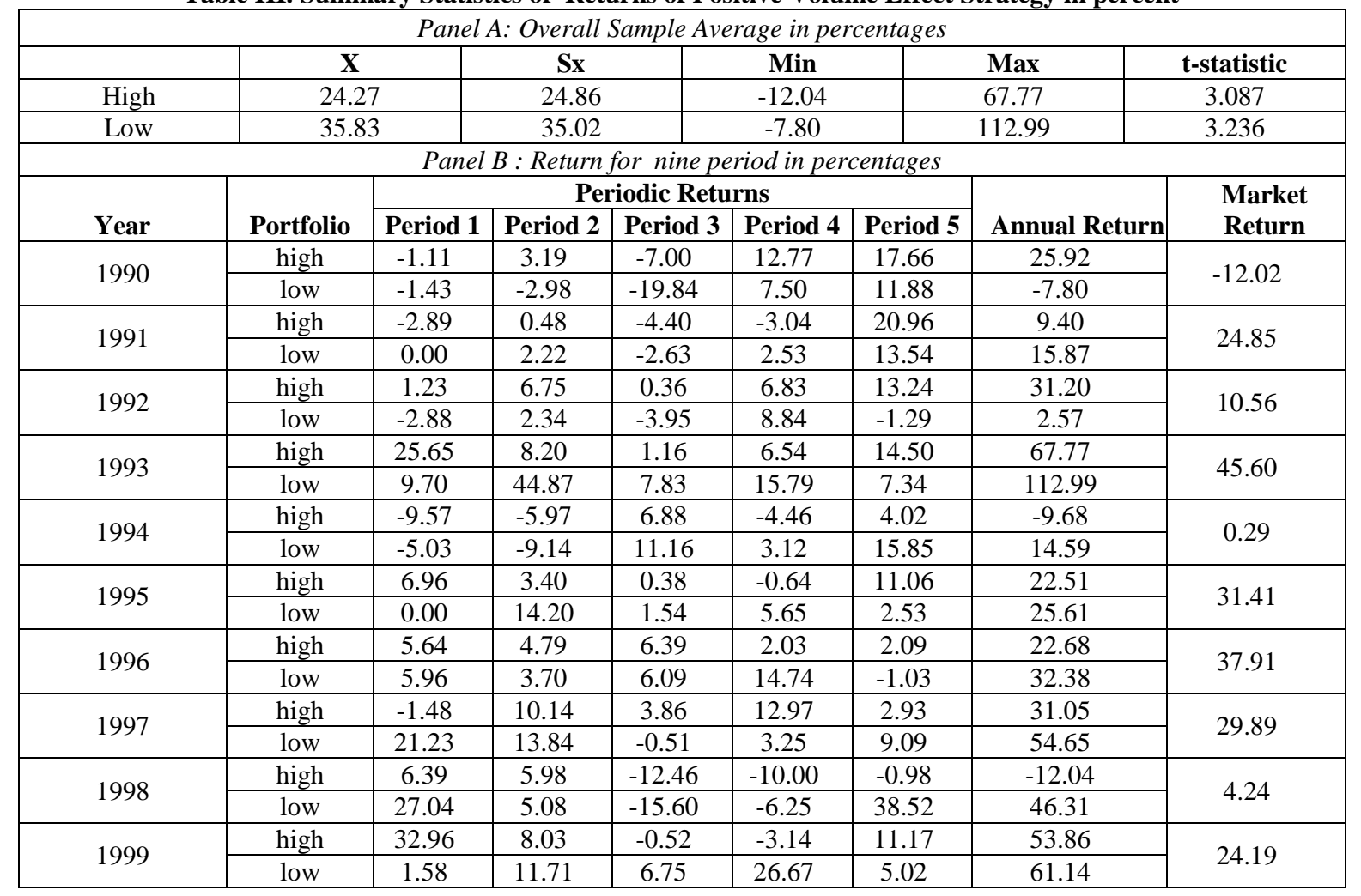

or previous week as follow;

$$
\mathrm{R}_{\mathrm{it}-1}=\left(\mathrm{P}_{\mathrm{it}-1}-\mathrm{P}_{\mathrm{it}-2}\right) / \mathrm{P}_{\mathrm{it}-2} \times 100
$$

where $\mathrm{P}_{\mathrm{it}-1}$ and $\mathrm{P}_{\mathrm{it}-2}$ are the weekly average prices in security $\mathrm{i}$ for week $\mathrm{t}-1$ and $\mathrm{t}-2$, respectively. We then combine the returns and trading activities to form four portfolios for week $\mathrm{t}$. These portfolios are formed by classifying securities based on the returns and trading activities of previous week (week t-1). At the end of each week (week $t)$, securities are classified into Winners $\left(\mathrm{R}_{\mathrm{it}-1}>0\right)$ or Losers $\left(\mathrm{R}_{\mathrm{it}-1}<0\right)$ and High or Low transaction $\left(\mathrm{u}_{\mathrm{it}-1}>0\right.$ or $\left.\mathrm{u}_{\mathrm{it}-1}<0\right)$. The weights in each of the four portfolios $(\mathrm{WH}, \mathrm{WL}, \mathrm{LH}$, and LL) for week $\mathrm{t}$ are:

where $\mathrm{Np}$ is the number of securities in each particular portfolio.

$$
\boldsymbol{W}_{i p t}=\left(\boldsymbol{R}_{i t-1}\left(1+\boldsymbol{u}_{i t-1}\right)\right) / \sum_{i=1}^{N p} \boldsymbol{R}_{i t-1}\left(1+\boldsymbol{u}_{i t-1}\right)
$$

The portfolio mean return for each week (week t), is calculated as below;

$$
\boldsymbol{X}_{p}=\sum_{i=1}^{N p} \boldsymbol{w}_{\text {ipt }} \boldsymbol{R}_{i t}
$$

The formation of portfolios were based on the past returns ( $\mathrm{W}$ or L, respectively Winner or Loser) and past trading activities ( $\mathrm{H}$ or L, respectively High or Low) of stocks in the formation period of a week. In Panel A, X is the annual average return (in percent) of each portfolio, and $\mathrm{Sx}$ is the sample standard deviation in percentage terms. 
Panel B shows returns for each portfolio in each of nine years. Weekly return for each year is the average weekly return for the year. Annual return for each year is compounded from weekly return using the following equations;

Annual Return $=($ Weekly Return/100+1 $) * * 52 * 100-100$

The results of our analysis appear in Table IV below. Our findings are partly consistent with Conrad, Hameed, and Niden (1994) who demonstrated that high-transaction securities experience price reversals whereas low transactions securities experience price continuation using NASDAQ and NMS data. In this study, winners keep winning and losers keep losing regardless of trading volumes. In other words, our results show price continuation without regard to transaction levels. On the contrary, in the study of Conrad et al. (1994), the price continuation occurs only with low transaction securities. That is, low transaction winners keep winning and low transaction losers keep losing but high transaction winners experience losing and high transaction losers experience winning. However, in our study, winners with high transaction always outperformed winners with low transaction and losers with high transaction most of time are out performed by losers with low transaction. Therefore, trading information on the TSE 100 still appears to be an important predictor of the returns of individual securities.

Table IV. Summary Statistics of Returns of Negative Volume Effect Strategy

\begin{tabular}{|c|c|c|c|c|c|c|}
\hline \multicolumn{7}{|c|}{ Panel A: Overall Sample Average in percentages } \\
\hline & \multicolumn{2}{|l|}{$\mathbf{X}$} & \begin{tabular}{|l|l}
$\mathbf{S x}$ & \\
\end{tabular} & Min & Max & t-stat \\
\hline $\mathrm{W}, \mathrm{H}$ & \multicolumn{2}{|c|}{175.37} & 55.03 & 69.27 & 253.27 & 10.077 \\
\hline $\mathrm{W}, \mathrm{L}$ & \multicolumn{2}{|c|}{60.29} & 33.23 & 4.78 & 104.94 & 5.737 \\
\hline $\mathrm{L}, \mathrm{H}$ & \multicolumn{2}{|c|}{-28.31} & 16.32 & -46.28 & -0.66 & -5.487 \\
\hline $\mathrm{L}, \mathrm{L}$ & -12.15 & & 21.69 & -50.54 & 19.76 & -1.771 \\
\hline \multicolumn{7}{|c|}{ Panel B: Return for each year in percentages } \\
\hline \multirow{2}{*}{ Year } & \multirow{2}{*}{ Period } & \multicolumn{4}{|c|}{ Returns of Portfolios } & \multirow{2}{*}{ Market Return } \\
\hline & & $\mathbf{W}, \mathbf{H}$ & $\mathbf{W}, \mathbf{L}$ & $\mathbf{L}, \mathbf{H}$ & $\mathbf{L}, \mathbf{L}$ & \\
\hline \multirow{2}{*}{1990} & Weekly & 1.02 & 0.28 & -1.19 & -1.34 & \\
\hline & Annual & 69.27 & 15.50 & -46.28 & -50.54 & -12.02 \\
\hline \multirow{2}{*}{1991} & Weekly & 2.46 & 1.17 & -0.83 & -0.41 & \\
\hline & Annual & 253.27 & 82.83 & -35.12 & -19.03 & 24.85 \\
\hline \multirow{2}{*}{1992} & Weekly & 1.77 & 0.66 & -0.52 & -0.50 & \\
\hline & Annual & 148.89 & 41.04 & -23.58 & -23.01 & 10.56 \\
\hline \multirow{2}{*}{1993} & Weekly & 2.27 & 1.39 & -0.39 & 0.14 & \\
\hline & Annual & 220.98 & 104.94 & -18.46 & 7.71 & 45.60 \\
\hline \multirow{2}{*}{1994} & Weekly & 1.43 & 0.09 & -0.64 & -0.85 & \\
\hline & Annual & 109.62 & 4.78 & -28.51 & -35.95 & 0.29 \\
\hline \multirow{2}{*}{1995} & Weekly & 1.98 & 1.08 & -0.01 & 0.35 & \\
\hline & Annual & 176.65 & 74.44 & -0.66 & 19.76 & 31.41 \\
\hline \multirow{2}{*}{1996} & Weekly & 1.87 & 0.78 & -0.10 & 0.08 & \\
\hline & Annual & 162.32 & 49.62 & -4.83 & 4.05 & 37.91 \\
\hline \multirow{2}{*}{1997} & Weekly & 2.16 & 1.24 & -0.90 & -0.05 & \\
\hline & Annual & 204.14 & 89.71 & -37.37 & -2.77 & 29.89 \\
\hline \multirow{2}{*}{1998} & Weekly & 2.22 & 0.82 & -1.18 & -0.48 & \\
\hline & Annual & 213.08 & 52.53 & -46.01 & -22.33 & 4.24 \\
\hline \multirow{2}{*}{1999} & Weekly & 2.11 & 1.22 & -1.05 & 0.01 & \\
\hline & Annual & 195.45 & 87.48 & -42.32 & 0.64 & 24.19 \\
\hline
\end{tabular}

For the annual and weekly returns of the four portfolios for the period between 1990 and 1999 shown in Table IV, winner portfolios always continued to win and always outperformed market returns whether they were high transaction or low transaction. However, high transactions always outperformed low transactions with significant differences. So, we conclude that information on trading activities appears to be an important factor in the TSE 100 . For loser portfolios, we observe something similar. Most of the time losers continued to lose or their profits were significantly lower than market returns, if any. So, losers were always outperformed by market returns. As far as the 
average annual returns, WH (winners with high transaction) portfolios and WL (winners with low transaction) portfolios achieved an astonishing return of $175.37 \%$ per year (significant at $\mathrm{t}=10.077$ ) and "moderate"-but-"stillsignificant" returns of $60.29 \%$ per year (significant at $t=5.737$ ), respectively. If we see losers, both LH (losers with high transaction) portfolios and LL (losers with low transaction) portfolios suffered the negative earnings of $-28.31 \%$ (significant at $\mathrm{t}=-5.487$ ) and $-12.15 \%$ per year (not significant at $\mathrm{t}=-1.771$ ), respectively. This finding is somewhat consistent with that of momentum strategy that buys past winners and sells past losers. As in momentum strategy, past winners continued to win and past losers continued to lose in a subsequent period. However, in this strategy past trading information combined with past returns seems to generate even more returns than the momentum strategy does.

The negative aspect of this strategy is the frequent portfolio rebalancing activities and accompanying increase in transaction costs. In this strategy, the portfolio is rebalanced every week. Therefore, accumulated transaction cost can be significant. These days however, due to the presence of discount dealers and steep competition in the transaction market, it is possible for even a nonprofessional to keep transaction cost down to less than $1 \%$ a week with a moderate amount of investment.

\section{CONCLUSION}

This study attempts to produce a better understanding of investment strategies based on past market information. It shows that aside form the momentum strategy that buys past winners and sells past losers, no other investment strategy investigated is consistent with findings in the U.S. market using the same strategies. While the Negative Volume Effect shows the importance of trading volume in constructing investment portfolios, our findings on the impact of such volume information are quite different from those documented by Conrad, Hameed and Niden (1994) in the U.S.. While Conrad et al. (1994) show that high-volume stocks experience price reversal whereas low volume stocks experience price continuation, this study shows a presence of price continuation for both low and high volume and that high volume winners always outperform low volume winners and low volume losers outperform high volume losers. The main conclusion of this study is that, investors who were long in past winners and short in past losers would consistently achieve above market return for the period of 1990 to 2000 . These findings are consistent with results of a previous study conducted by Foerster, Prihar and Schmitz (1995) for the period 1977-1992. The momentum effect seems to be a characteristic of the Canadian market which is evidence of price continuation in this market. The robustness of the price continuation hypothesis within this market and the information content of trading volumes could be related to the nature and the importance of this market as compared to the U.S. market.

\section{REFERENCES}

1. Assogbavi, T. and J. Dodge, 2002, Momentum Profits Using Spread Midpoint Returns and Trading Volume on the Nigeria Stock Exchange, Journal of African Finance and Economic Development, vol. 5, p 65.

2. Assogbavi, T., N. Khoury, and P. Yourougou, 1995, Short Interest and The Asymmetry of the Price-Volume Relationship in the Canadian Stock Market, Journal of Banking And Finance 19, 1341-1358.

3. Basu, S., Investment Performance of Common Stocks in Relation to Their Price-Earnings Ratios: A Test of the Efficient Market Hypothesis. Journal of Finance 3 (June 1977), 663-82.

4. Baytas, A., C. Nusret, 1999, Do Market Overact: International Evidence, Journal of Banking \& Finance, July. 1999, vol.23 no.7 p1121-1144.

5. Blume, L. D. Easley, and M. O'Hara, 1994, Market Statistics and Technical Analysis: The role of Volume, Journal of Finance 49, 153-181.

6. Campbell, J. Y., S. J. Grossman, and J. Wang, 1993, Trading Volume and Serial Correlation in Stock Returns, Quarterly Journal of Economies 108, 905 940.

7. Chan Kaloc, Allaudeen Hameed, Wilson Tong, 1999, Profitability of Momentum Strategies in the International Equity Markets, Working Paper, Hong Kong University of Science \& Technology

8. Chordia, T., and B. Swaminathan, 2000, Trading Volume and Cross-Autocorrelations in Stock Returns, Journal of Finance, Vol. IV, No 2, April 2000, 913-935. 
9. Cleary, Sean, Michael Inglis, 1998, Momentum in Canadian Stock Returns, Canadian Journal of

Administrative Sciences (Revue Canadienne des Sciences de l'Administration), Montreal; Sep 1998; Vol. 15, Issue. 3; pg. 279, 13 pgs.

10. Conrad, Hameed, and Niden, 1994, Volume and Autocovariances in Short Horizon Individual Security Returns, Journal of Finance 49, 1305-1329.

11. DeBondt Werner F.M., Richard Thaler, 1985, Does the Stock Market Overreact? The Journal of Finance 1985 Jul. p793-808.

12. Dirk, S., W. DeBondt, and M. Weber, 1999, Contrarian and Momentum Strategies in Germany, Financial Analysts Journal 1999 Nov/Dec p104-116.

13. Dreman, D. N., The New Contrarian Investment Strategy. New York: Random House, 1982.

14. Foerster, S., A. Prihar, and J. Schmitz, 1995, Back to the future, Canadian Investment Review 7, 9-13.

15. Gervais, S., R. Kaniel and D. Mingelgrin, 2001, The High-Volume Return Premium, Journal of Finance, Vol. LVI, No. 3, June 2001.

16. Lee, C., and B. Swaminathan, 2000, Price Momentum and Trading Volume, Journal of Finance, Vol. V, No 5, Oct. 2000, 2017-2069.

17. Lehmann, Bruce N., 1990, Fads, Martingales, and Market Efficiency, Quarterly Journal of Economics 105, $1-28$.

18. Mayshar, Joram, 1983, On Divergence of Opinion and Imperfections in Capital Markets, American Economic Review 73, 114-128.

19. Merton, Robert C., 1987, A Simple Model of Capital Market Equilibrium with Incomplete Information, Journal of Finance 42, 483-510.

20. Miller, Edward M., 1979, Risk, Uncertainty, and Divergence of Opinion, Journal of Finance 32, 1151-1168.

21. Mun, J.C., G.M. Vasconcellos, R. Kish, 2000, The Contrarian/Overreaction Hypothesis: An Analysis of the US and Canadian Stock Markets, Global Finance Journal 11 (2000) 53-72.

22. Narasimhan, Jegadeesh, Sheridan Titman, 1993, Returns to Buying Winners and Selling Losers: Implications for Stock Market Efficiency, Journal of Finance, Mar.1993 p65-h91.

23. Rouwenhorst, K. G., 1999, Local Return factors and Turnover in Emerging Stock Markets, The Journal of Finance, Cambridge; Aug 1999; Vol. 54, Issue 4; pg. 1439, 26 pgs.

24. Rouwenhorst, K.G., 1998, International Momentum Strategies, Journal of Finance, 53, 267-284.

25. Ying, Charles C., 1966, Stock Market Prices and Volumes of Sales, Econometrica 34, 676-685. 